\title{
Multiple copies of the pyruvate kinase gene affect yeast cell growth
}

\author{
Paul A. Moore, Andrew J. E. Bettany $\dagger$ and Alistair J. P. Brown* \\ Department of Molecular and Cell Biology, University of Aberdeen, Marischal College, Aberdeen AB9 1AS, UK
}

(Received 5 June 1990; revised 1 August 1990; accepted 8 August 1990)

\begin{abstract}
The Saccharomyces cerevisiae pyruvate kinase gene (PYKI) was transformed into yeast using the multicopy vector pJDB207. Growth rates and $P Y K 1$ gene expression levels varied considerably amongst the transformants. Yeast transformants expressing the $P Y K 1$ gene at high levels formed small colonies compared with those expressing the gene at relatively low levels. Slow-growing transformants 'reverted' at high frequency to more rapid growth, and this correlated with decreases in $P Y K 1$ gene copy number and $P Y K 1$ mRNA abundance. This apparent selection against $P Y K 1$ over-expression was disrupted by the introduction of a stop codon at the $5^{\prime}$-end of the $P Y K 1$ coding region, thus confirming that the growth effects were mediated by the PYK1 gene. However, massive overproduction of pyruvate kinase in yeast, using multiple copies of a PGK:PYK gene fusion, had no significant effect upon cell growth. This suggests that the deleterious effect upon the host yeast cell is mediated by abnormally high levels of the wild-type gene or PYK1 mRNA, rather than by increased pyruvate kinase levels.
\end{abstract}

\section{Introduction}

During fermentative growth, the glycolytic enzymes can comprise over $30 \%$ of soluble cell protein in the yeast Saccharomyces cerevisiae (Fraenkel, 1982). The glycolytic genes are among the most efficiently expressed genes in this organism, and most have been isolated and sequenced (Holland \& Holland, 1979; Holland et al., 1981; Alber \& Kawasaki, 1982; Bennetzen \& Hall, 1982; Hitzeman et al., 1982; Watson et al., 1982; Burke et al., 1983; Kopetzki et al., 1985; Kellermann et al., 1986; Aguilera \& Zimmerman, 1986; Stachelek et al., 1986; Tekamp-Olson et al., 1988; White \& Fothergill-Gilmore, 1988; Heinisch et al., 1989; McNally et al., 1989; Schwelberger $e t$ al., 1989). It is frequently assumed that glycolytic gene expression is increased when yeast cultures are transferred from nonfermentative to fermentative carbon sources, but this is not the case for all strains of Saccharomyces (Clifton \& Fraenkel, 1981).

Pyruvate kinase catalyses the last energy-conserving reaction in the glycolytic pathway. The enzyme converts phosphoenolpyruvate and ADP to pyruvate and ATP, and this is one of the irreversible steps on the pathway.

† Present address: AFRC Institute for Grassland and Environmental Research, Welsh Plant Breeding Station, Aberystwyth, Dyfed SY23 3EB, UK.

Abbreviations: $P Y K 1$, pyruvate kinase gene; $P G K 1$, phosphoglycerate kinase gene; $H X K 1, H X K 2$ hexokinase genes; $P G I 1$, phosphoglucose isomerase gene, $P F K 2$, phosphofructokinase gene; $T P I 1$, triosephosphate isomerase gene; $P G M I$, phosphoglyceromutase gene.
The yeast enzyme, which is a tetramer of four identical $55 \mathrm{kDa}$ subunits, responds to a number of allosteric effectors, including fructose-1,6-diphosphate and $\mathrm{NH}_{4}^{+}$ (Hunsley \& Suelter, 1969; Yoshino \& Murakami, 1982). Pyruvate kinase is one of the first glycolytic enzymes to be induced when glucose is added to yeast cultures growing on acetate (Maitra \& Lobo, 1971). These observations suggest that under some conditions pyruvate kinase contributes significantly to the regulation of glycolytic flux.

Owing to the high efficiency of yeast glycolytic gene expression, promoters from several of these genes, including $P Y K 1$, have been used to drive the expression of a large number of heterologous proteins in yeast (for reviews see Kingsman et al., 1985; Goodey et al., 1987; King et al., 1989). In several cases, the expression of a particular heterologous sequence has been compared with that of the appropriate wild-type glycolytic gene on a similar multicopy plasmid (e.g. Chen et al., 1984; Mellor et al., 1985). These experiments have demonstrated that the expression of some glycolytic genes can be markedly increased without affecting yeast growth or viability. In this paper we describe the effects of over-expressing the $P Y K 1$ gene upon the yeast cell. These effects set the $P Y K 1$ gene apart from most other glycolytic genes.

\section{Methods}

Yeast strains and plasmids. The $S$. cerevisiae strains DBY746 (MAT $\alpha$ his3 leu 2 trpl ura $3\left[\mathrm{cir}^{+}\right]$) and X4003-5B (MATa adeI gall his4 leu 2 met2 trp5 ura $3\left[\mathrm{cir}^{+}\right]$) were used throughout. The plasmids used in this study 


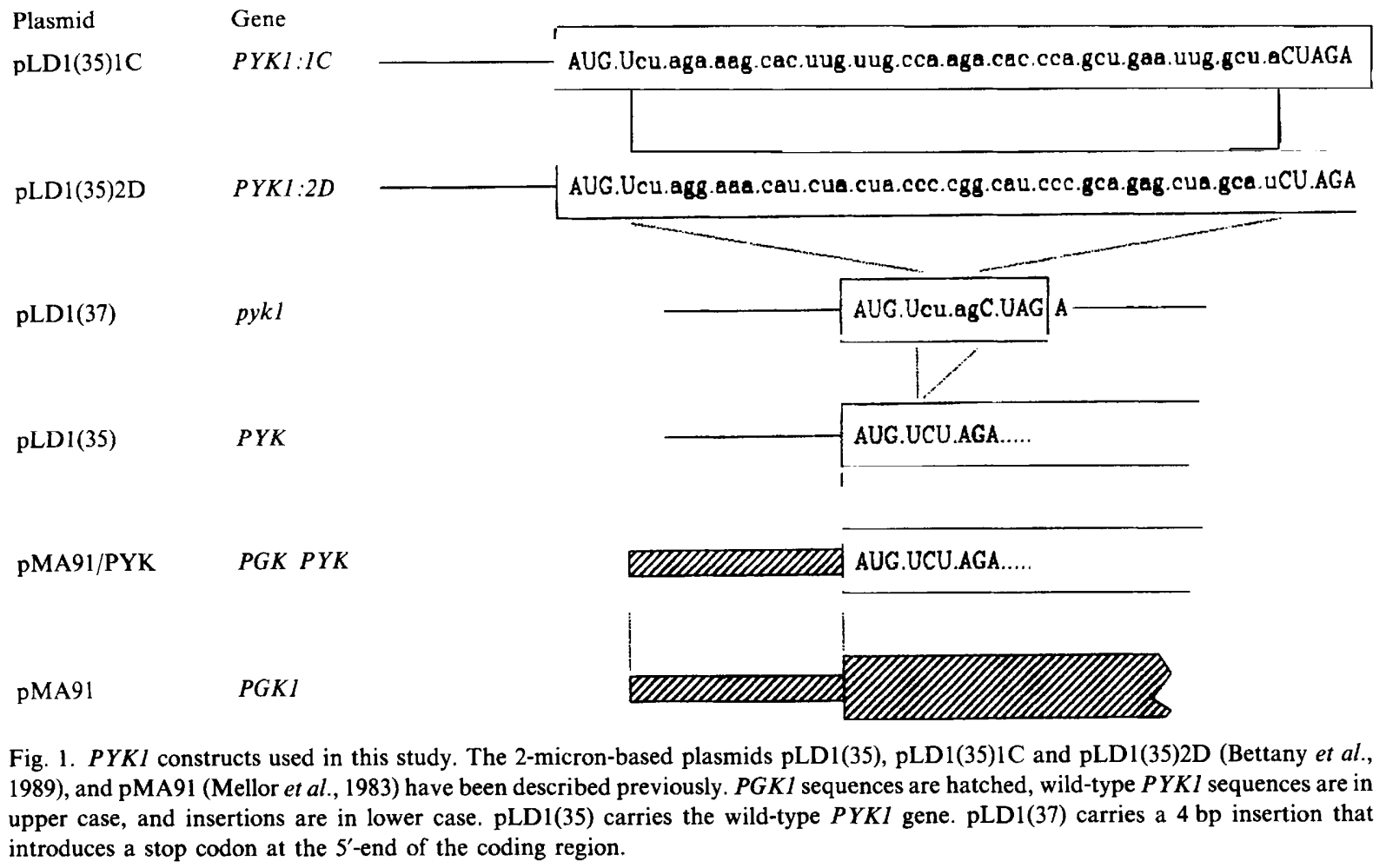

are illustrated in Fig. 1. Following yeast transformation (Beggs, 1978), the phenotypic markers of all transformants were checked before further analysis.

Starter cultures were grown with shaking for $2 \mathrm{~d}$ at $30^{\circ} \mathrm{C}$ under selective conditions in GYNB $(2 \%$, w/v, glucose, $0.65 \%$ yeast nitrogen base containing the appropriate supplements). These cultures were used to inoculate fresh minimal (GYNB) or rich medium [YEPD; $2 \%$ glucose, $2 \%$ bacteriological peptone, $1 \%$ yeast extract, all $(\mathrm{w} / \mathrm{v})$ as specified] and cultures were grown with shaking at $30^{\circ} \mathrm{C}$ to midexponential growth phase $\left(\mathrm{OD}_{600}=0 \cdot 4-0 \cdot 6\right)$, whereupon cells were harvested for analysis. For the growth experiments, transformants were serially subcultured for 75 generations in minimal medium. These cultures were subcultured in the late exponential growth phase $\left(\mathrm{OD}_{600}=0.8-1.0\right)$ into fresh GYNB lacking leucine (starting $\mathrm{OD}_{600}=0.05$ ), to select for maintenance of the $L E U 2$ plasmid marker. Growth of cultures was monitored spectrophotometrically using their optical density at $600 \mathrm{~nm}$.

Filter hybridizations. For Northern blotting, total yeast RNA was prepared as described by Lindquist (1981), denatured by heattreatment in the presence of formaldehyde, electrophoresed on $1.5 \%$ (w/v) agarose gels containing formaldehyde (Lehrach et al., 1977), and transferred to nitrocellulose or nylon membranes (Thomas, 1980). Filters were probed and Southern blotting was performed as described by Santiago et al. (1986).

Dot-blotting was used for measuring $P Y K I$ gene copy number and $P Y K I$ mRNA abundance (Purvis et al., 1987). Briefly, denatured DNA or RNA samples were dotted onto nitrocellulose filters using a Hybridot apparatus (BRL). Multiple dilutions of each sample were dotted in duplicate. Filters were baked, prehybridized, probed and washed as described previously (Santiago et al., 1986). Filters were autoradiographed to check for background, and the individual dots were then cut out, and the bound radioactivity measured by scintillation counting. These values were only used if control dilution series confirmed that the hybridization had been performed under quantitative conditions (Santiago et al., 1986). mRNA levels were measured relative to the actin mRNA to correct for differences in RNA yield between samples (Santiago et al., 1986). Similarly, $P Y K 1$ gene copy numbers were estimated relative to the single-copy chromosomal actin gene (Purvis et al., 1987). More recently, accurate quantification of $P Y K 1$ and actin mRNA levels was achieved directly from Northern blots using the AMBIS 2D-Radioimaging System.

Hybridization probes were prepared by nick-translating or random priming plasmid DNA or purified DNA fragments (Maniatis et al., 1975; Feinberg \& Vogelstein, 1983). The abundance of PYKI mRNA was measured using nick-translated PSPK2, which contains the $511 \mathrm{bp}$ $X b a \mathrm{I} / B g l \mathrm{II}$ fragment from the coding region cloned into pSP64 (Santiago et al., 1987). The actin mRNA was analysed using nicktranslated pSPACT9, which contains the $1.5 \mathrm{~kb}$ BamHI/Hind III fragment of the actin gene (Gallwitz \& Sures, 1980) cloned into pSP64. Copy number estimations were done using random-primed probes generated using purified $X b a \mathrm{I} / B g / \mathrm{II} P Y K 1$ and $B a m \mathrm{HI} /$ Hind III actin fragments from pSPK2 and pSPACT9, respectively.

\section{Results}

\section{PYK1 transformants differ in their growth rates}

The plasmid pLD1(35) comprises a $6 \cdot 3 \mathrm{~kb}$ yeast genomic fragment cloned between the HindIII and NdeI sites of the multicopy vector pJDB207 (Parent et al., 1985; Bettany et al., 1989). The wild-type $P Y K I$ gene on this plasmid (Fig. 1) complements the conditionally-defec- 


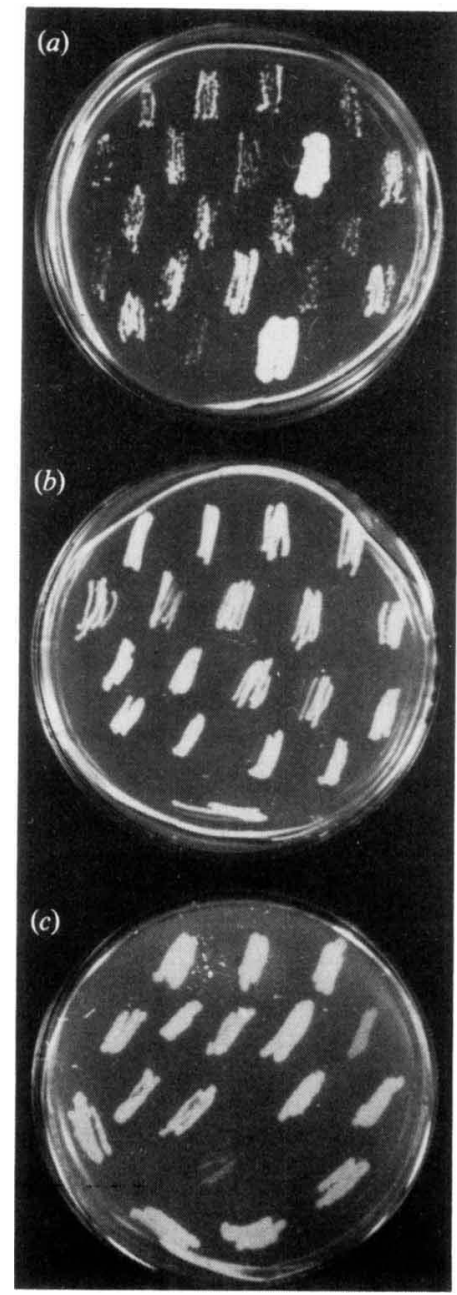

Fig. 2. Growth of transformants carrying multicopy $P Y K I$ or pykI plasmids. $(a, b)$ DBY746 was transformed with pLD1(35). Fresh transformants were patched onto minimal agar lacking leucine and incubated at $30^{\circ} \mathrm{C}$ for $5 \mathrm{~d}(a)$. This plate was then stored for 1 week at $4{ }^{\circ} \mathrm{C}$, after which each transformant was then repatched onto fresh minimal agar minus leucine, and grown at $30^{\circ} \mathrm{C}$ for a further $5 \mathrm{~d}(b)$. (c) Fresh DBY746:pLD1(37) transformants treated identically to $(a)$.

tive pykl alleles pykl-5 and $c d c 19$ at their restrictive temperatures (Bettany et al., 1989). In early experiments to study $P Y K 1$ gene expression we noted that yeast transformation frequencies obtained with pLD1(35) were routinely 10 - to 100 -fold lower than the transformation frequencies obtained for other multicopy yeast vectors. This was the case when DBY746 or X4003-5B was used as the host yeast strain, or when the closely related multicopy plasmid pAYE4(34), which carries the wild-type $P Y K 1$ gene, was used. Furthermore, we and others noted that pLD1(35) and pAYE4(34) transformants displayed a wide range of colony sizes when grown on rich or minimal media (Andrew Goodey, personal communication). While some transformants displayed strong growth on minimal plates, the majority grew weakly (Fig. $2 a$ ). This was reflected in the performance of DBY746:pLD1(35) transformants in minimal medium, with the doubling times of individual transformants ranging from $2 \mathrm{~h}$ to over $5 \mathrm{~h}$. In contrast, no such effects were observed when the same strains were transformed with the vector alone (pJDB207).

Slow-growing pLD1(35) transformants 'reverted' to more rapid growth with high frequency, even under conditions that select for the plasmid-borne LEU2 marker. Transformants that initially grew slowly, grew relatively normally when repatched onto fresh minimal medium (Fig. $2 b$ ). This phenomenon has been observed consistently in our laboratory and in other laboratories (Andrew Goodey, personal communication; Teresa McNally \& Linda Gilmore, personal communication; Toby Murcott, personal communication). Furthermore, similar effects were observed for the plasmids pLD1(35)1C and pLD1(35)2D (Bettany, 1988). These plasmids are derivatives of pLD1(35) which contain $42 \mathrm{bp}$ insertions at the $5^{\prime}$-end of the $P Y K I$ coding region (Fig. 1). The $P Y K 1: I C$ and $P Y K 1: 2 D$ insertion mutants, which have been used to analyse the effect of nonpreferred codons upon the translation of the $P Y K 1$ mRNA, retain at least partial pyruvate kinase activity (Bettany et al., 1989).

\section{Slow growth correlates with high PYKI expression levels}

The abundance of $P Y K I$ mRNA was measured relative to actin mRNA in more than thirty DBY746:pLD1(35) transformants. Actin mRNA was used as an internal control for minor variations in RNA yield. Data were only used if hybridizations were proven experimentally to have taken place under conditions of probe-excess (see Methods). The abundance of the $P Y K 1$ mRNA was $0.6 \%$ of total mRNA in the untransformed host strain. $P Y K I$ mRNA levels varied considerably amongst transformants, from less than $1.0 \%$ up to $10 \%$ of total mRNA. These quantitative measurements of $P Y K I$ mRNA abundance obtained by dot-blotting were confirmed qualitatively by Northern analysis (Fig. 3). Significantly, slow-growing transformants contained relatively high levels of $P Y K I \mathrm{mRNA}$ (typically more than $1.5 \%$ of total mRNA) compared with fast-growing transformants (typically less than $1.5 \%$ of total mRNA).

\section{Abnormally high PYK1 transcript levels 'wind down' during growth}

As described above, pLD1(35), pAYE4(34), pLD1(35)1C or pLD1(35)2D transformants with high $P Y K 1$ mRNA levels grew relatively slowly, and these slow-growing transformants quickly 'reverted' to rapid 

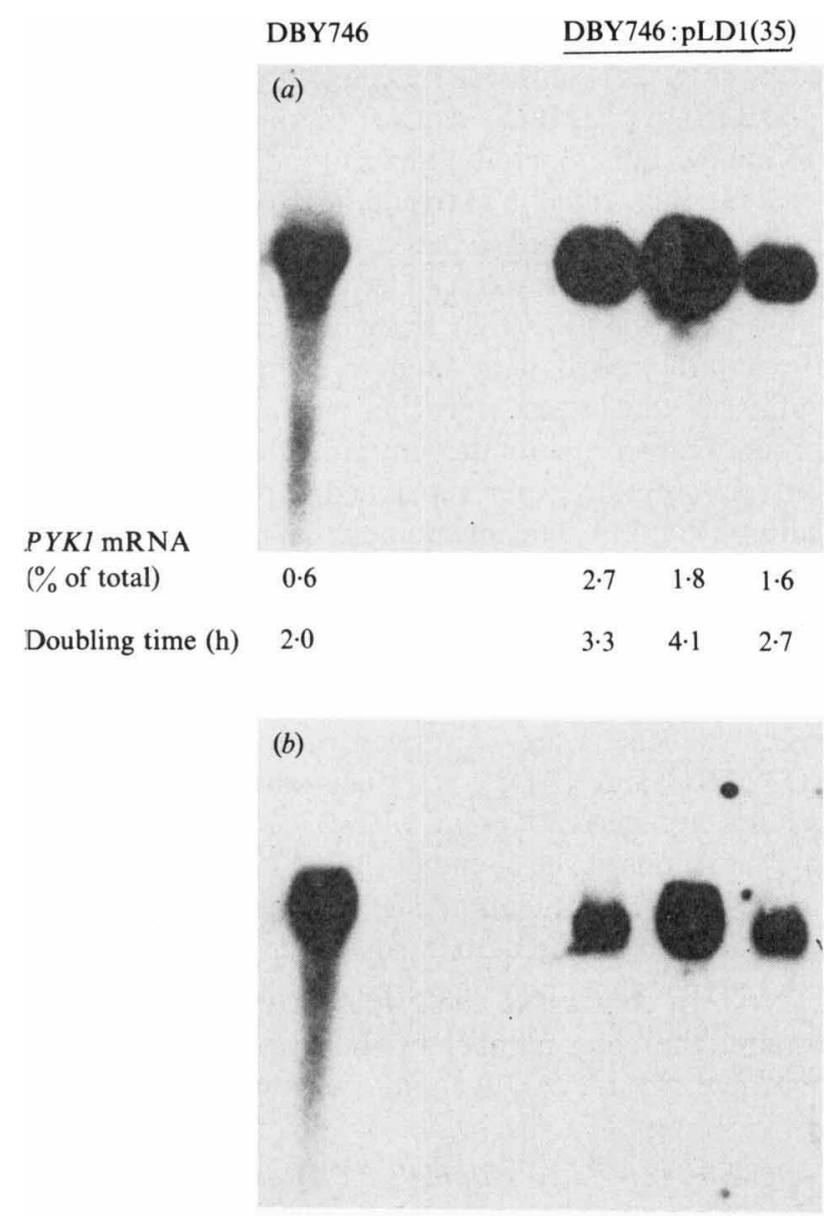

Fig. 3. Northern analysis of the $P Y K 1$ mRNA in pLD1(35) transformants. RNA isolated from DBY746 and three slow-growing pLD1(35) transformants was subjected to Northern analysis. The filter was probed for $P Y K 1$ mRNA (a), the probe was stripped from the filter, and the filter then probed for actin mRNA (b). At each stage the amount of bound radioactivity in each band was determined using an AMBIS 2D-Radioimaging System. Note that the amount of total RNA loaded in each lane differs for each sample.

growth (Fig. 2). However, amongst different pLD1(35) transformants the relationship between $P Y K 1 \mathrm{mRNA}$ abundance and the doubling time of the culture was not linear. For example, in Fig. 3 the transformants containing PYKl mRNA levels of $1.6 \%$ and $1.8 \%$ of total mRNA had doubling times of 2.7 and $4.1 \mathrm{~h}$, respectively, and yet the transformant with a $P Y K 1$ mRNA level of $2.7 \%$ of total mRNA had a doubling time of $3.3 \mathrm{~h}$. Nevertheless, we consistently observed that transformants containing significantly elevated $P Y K I$ mRNA levels grew more slowly than the untransformed host strain.

To confirm the generality of the relationship between slow growth and elevated $P Y K 1 \mathrm{mRNA}$ levels, a range of transformants were analysed in detail. RNA was prepared from the transformants before and after storage
Table 1. Effect of storage upon PYK1 mRNA levels in DBY746 transformants

\begin{tabular}{llcc}
\hline \hline & & \multicolumn{2}{c}{$\begin{array}{c}\text { PYK1 mRNA level } \\
(\% \text { of total mRNA) }\end{array}$} \\
\cline { 3 - 4 } Strain & Plasmid & $\begin{array}{l}\text { Before } \\
\text { storage* }\end{array}$ & $\begin{array}{c}\text { After } \\
\text { storage }\end{array}$ \\
\hline DBY746 & - & $0 \cdot 6$ & $0 \cdot 6$ \\
WM4 & pLD1(35) & 8.9 & $1 \cdot 0$ \\
WM5 & pLD1(35) & $4 \cdot 0$ & $1 \cdot 1$ \\
1CN2 & pLD1(35)1C & $1 \cdot 3$ & $1 \cdot 5$ \\
1CM6 & pLD1(35)1C & $4 \cdot 2$ & $1 \cdot 1$ \\
2DN1 & pLD1(35)2D & 4.6 & $0 \cdot 6$ \\
2D8 & pLD1(35)2D & $1 \cdot 4$ & $1 \cdot 1$ \\
\hline \hline
\end{tabular}

* PYK1 mRNA abundance determined immediately following transformation.

$\dagger P Y K I$ mRNA abundance redetermined after each transformant had been stored on minimal plates for about 8 weeks at $4{ }^{\circ} \mathrm{C}$.

for about 8 weeks at $4{ }^{\circ} \mathrm{C}$ on minimal agar lacking leucine. The abundance of the $P Y K 1$ mRNA in each RNA sample was then measured (Table 1). In all cases where the abundance of the $P Y K l$ mRNA was initially greater than $1.5 \%$ of total mRNA, the $P Y K 1 \mathrm{mRNA}$ was found to have decreased following storage. This correlated with 'reversion' to rapid growth. No significant changes in $P Y K 1$ mRNA abundance were observed where the initial level was less than $1.5 \%$ of total mRNA (Table 1).

In an attempt to confirm that $P Y K 1$ over-expression causes the deleterious effect upon the growth of the host yeast cell, and that the 'wind-down' in PYKl overexpression correlates with the 'reversion' of slowgrowing transformants to more rapid growth, a slowgrowing transformant was studied. Strain X4003-5B was transformed with pLD1(35) (Fig. 1), and a transformant that had formed a small colony, and was therefore presumed to have an abnormally slow growth rate, was picked for further analysis. The doubling time of the transformant was initially twice that of the untransformed strain (which has a doubling time of about $2 \mathrm{~h}$ ), and decreased by approximately $45 \%$ during growth in selective broth for 75 generations (Fig. 4a).

DNA and RNA were prepared at specific time points to determine $P Y K 1$ gene copy number and $P Y K 1 \mathrm{mRNA}$ abundance during this prolonged growth (Fig. $4 a$ ). Initially, this transformant carried, on average, about 20 copies of the $P Y K 1$ gene per haploid genome, and the abundance of the $P Y K 1 \mathrm{mRNA}$ was over fivefold that of the untransformed host $(0.6 \%$ of total mRNA; Purvis et al., 1987). After about 45 generations of growth, significant decreases were observed both in gene dosage and in mRNA abundance for PYK1 (relative to actin), and these correlated with an increase in growth rate (Fig. 

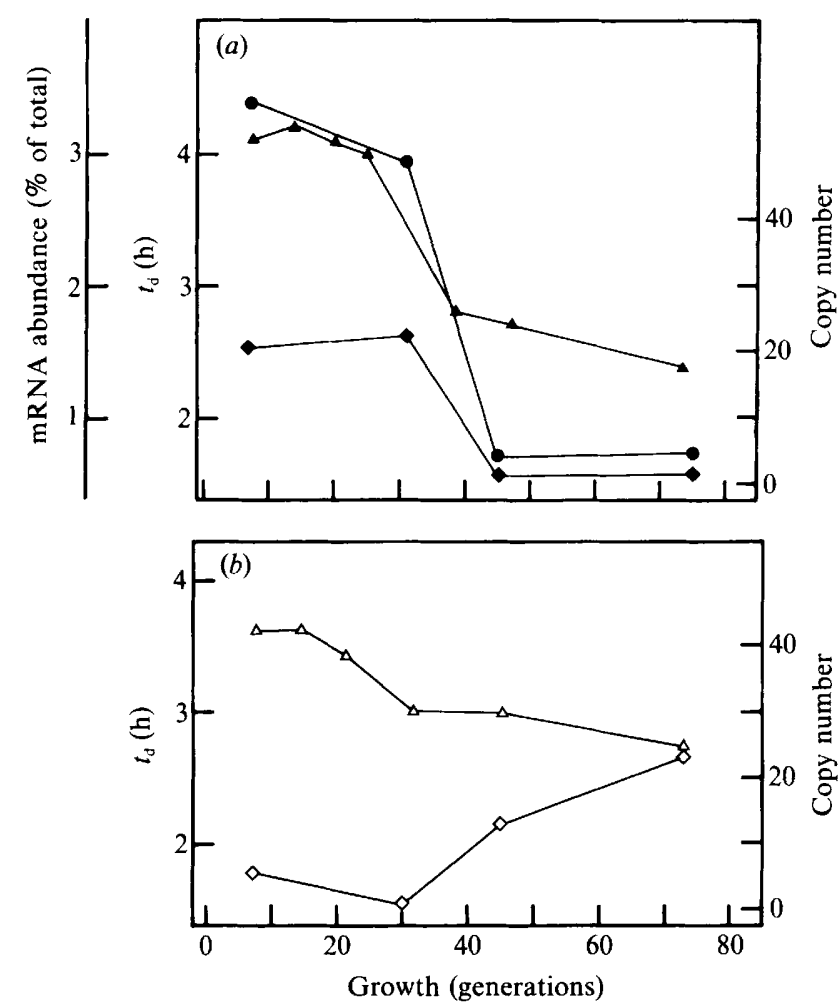

Fig. 4. Abnormally high levels of $P Y K 1$ expression decrease during growth. $P Y K 1$ copy number and mRNA abundance were measured during serial batch growth of a slow-growing X4003-5B:pLD1(35) transformant ( $a$; closed symbols), and a X4003-5B : pLD1(37) transformant ( $b$; open symbols). Fresh cultures were inoculated from cultures that had reached late-exponential growth phase. Doubling times, $t_{\mathrm{d}}(\mathbf{\Delta}$, $\triangle$ ) were measured as $O_{600} . P Y K 1$ mRNA abundance (O) is expressed as a percentage of total $\mathrm{mRNA}$, and $P Y K I$ copy number $(\bullet$, $\diamond)$ is expressed per haploid genome.

4a). The copy number of the $P Y K 1$ gene approached normality and the abundance of the mRNA approached wild-type levels. Southern blot analysis confirmed the existence of both chromosomal and plasmid-encoded $P Y K 1$ sequences throughout the experiment and confirmed the changes in the relative abundance of these sequences (not shown). No new plasmids (which might have formed via recombination with the endogenous 2micron plasmid) were detected.

\section{Inactivation of PYKI disrupts the effect upon growth rate}

The previous experiments confirmed that increasing growth rates of pLD1(35) transformants correlate with decreasing levels of $P Y K I$ gene expression. However, they failed to exclude the possibility that the growth rate effect is mediated by sequences other than $P Y K 1$ in pLD1(35). The CYC3 and FUN11 genes are located $5^{\prime}$ and $3^{\prime}$ to the PYKl gene on chromosome 1 (Coleman et al., 1986). Comparing the restriction map of this region of chromosome 1 (Coleman et al., 1986) with that of the genomic insert of pLD1(35) (Burke et al., 1983) suggests that while the entire $C Y C 3$ gene is probably present in pLD1(35), it is likely that only part of the FUN11 gene is present. Therefore, these genes may have contributed at least partially to the growth effects described above. The plasmid pLD1(37) was constructed to exclude this possibility. pLD1(37) is identical to pLD1(35) except for the insertion of a premature termination codon at the $\mathrm{N}$ terminus of the $P Y K 1$ coding region (Fig. 1).

Fresh X4003-5B:pLD1(37) transformants generally showed strong growth on plates, in contrast to fresh pLD1(35) transformants (Fig. 2c). A pLD1(37) transformant was then subjected to detailed analysis during prolonged growth over about 75 generations in a similar experiment to that described above for pLD1(35). As before, $p y k 1$ copy number and mRNA abundance were quantified by dot-blotting, and the doubling time of the culture was measured using the optical density at $600 \mathrm{~nm}$. During prolonged growth there was no significant change in the abundance of the pykl mRNA above the level of the untransformed host strain $(0.6 \%$ of total mRNA). In contrast to the X4003-5B :pLD1(35) transformant, the copy number of the pykl gene increased about fivefold to over 20 copies per haploid genome in cells carrying pLD1(37) while the doubling time of the culture decreased by $23 \%$ (Fig. $4 b$ ). Hence the negative effects upon growth are mediated by $P Y K I$ and are not due to other plasmid-borne sequences since plasmid copy number increased during the experiment. Therefore, high levels of $P Y K 1$ gene expression inhibit growth of the host yeast cell, thus creating a strong selection against this over-expression.

The growth effects are not due to high intracellular levels of pyruvate kinase

It seemed likely that the effects of high levels of $P Y K 1$ gene expression upon growth were mediated by excess pyruvate kinase. This was tested using the plasmid pMA91/PYK (a generous gift from Jane Mellor, University of Oxford, UK). This multicopy plasmid carried a $P G K: P Y K$ gene fusion in which the $P G K 1$ promoter and $5^{\prime}$-untranslated region were fused to the $P Y K 1$ coding and $3^{\prime}$-untranslated regions to regenerate the correct $P Y K 1$ coding sequence (Fig. 1). pMA91/PYK transformed DBY746 more efficiently than plasmids which carried the wild-type $P Y K I$ gene.

Protein extracts prepared from DBY746, or DBY746 transformants carrying pMA91/PYK or pLD1(35), were subjected to SDS-PAGE (Fig. 5). Only limited overproduction of pyruvate kinase was apparent in the pLD1(35) transformants which had PYKI mRNA 


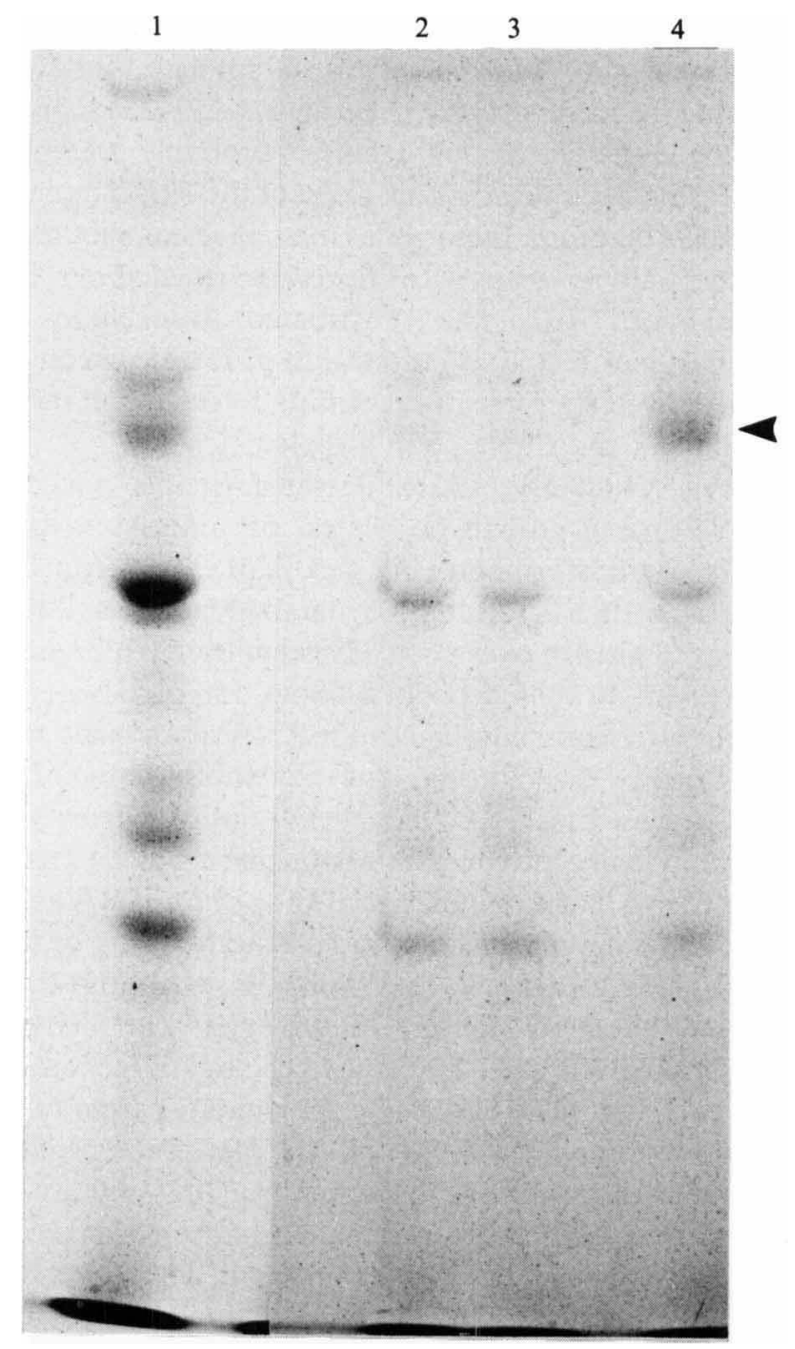

Fig. 5. Synthesis of high levels of pyruvate kinase using a $P G K: P Y K$ gene fusion. Total soluble protein extracts from DBY746 (1), two DBY746:pLD1(35) transformants $(2,3)$, and a DBY746:pMA91/ PYK transformant (4) were electrophoresed on an $8 \%(\mathrm{w} / \mathrm{v})$ polyacrylamide/SDS gel and stained with Coomassie blue. The abundances of the $P Y K 1$ mRNA (or $P G K / P Y K$ mRNA in the case of the DBY746: pMA91/PYK transformant) were $0.6 \%, 0.9 \%, 1.6 \%$ and $5.5 \%$ of total mRNA, respectively, as measured by dot-blotting and confirmed by Northern analysis (not shown). The loading for DBY746 is greater than for the transformants. The arrow indicates the pyruvate kinase band.

abundances of $0.9 \%$ and $1.6 \%$ of total mRNA. Massive overproduction of pyruvate kinase was observed in the pMA91/PYK transformant which had a $P G K: P Y K l$ mRNA abaundance of $5.5 \%$ of total mRNA. However, this pMA91/PYK transformant grew as strongly as the untransformed strain (as did pMA91/PYK transformants in general). Therefore, the deleterious effects of multicopy plasmids carrying the wild-type $P Y K I$ gene were not due to the synthesis of excess pyruvate kinase.

\section{Discussion}

We have demonstrated that abnormally high levels of the wild-type $P Y K 1$ gene or mRNA have a deleterious effect upon the growth of yeast, which creates a strong selection for reduced $P Y K 1$ copy numbers. Presumably the decrease in the average $P Y K 1$ gene and mRNA levels during prolonged growth or storage of high-copy-number pLD1(35) transformants was mediated by unequal partitioning of this pJDB207-based vector during cell division (Futcher \& Cox, 1984) followed by more rapid growth of cells carrying reduced $P Y K I$ copy numbers. This selection is disrupted by inactivating the $P Y K I$ gene with a premature stop codon, allowing the copy number to drift upwards during prolonged growth in medium lacking leucine, presumably owing to selection for increased copy number of the partially active $L E U 2 d$ allele carried on the vector pJDB207 (Futcher \& Cox, 1984). pJDB207 contains only one half of the 2-micron inverted repeat, and therefore is unable to use the natural mechanism for 2-micron amplification, which depends upon recombination between the two halves of the repeated sequence (Murray et al., 1987). In summary, the selection for a reduction in $P Y K 1$ copy number dominates over that for an increase in $L E U 2 d$ copy number.

The observations that high $P Y K I$ copy numbers affect cell growth, and that the over-expression of $P Y K 1$ is limited by at least two dosage compensation mechanisms (Moore et al., 1990), appear to set this gene apart from most other glycolytic genes. It has become clear that yeast can tolerate extremely high levels of expression from most other glycolytic genes with little apparent effect upon cell growth or viability. These include the $H X K 2, P G I 1, T P I 1, P G K 1$ and $P G M 1$ genes (Alber \& Kawasaki, 1982; Kawasaki \& Fraenkel, 1982; Mellor et al., 1985; Aguilera \& Zimmerman, 1986; Schaaf et al., 1989).

It is important to note that excess pyruvate kinase itself does not inhibit growth, and in this respect the enzyme is similar to hexokinase, phosphoglucose isomerase, triosephosphate isomerase, phosphoglycerate kinase and phosphoglycerate mutase (Alber \& Kawasaki, 1982; Kawasaki \& Fraenkel, 1982; Chen et al., 1984; Mellor et al., 1985; Aguilera \& Zimmerman, 1986; Schaaf et al., 1989). The relatively normal behaviour of the pLD1(37) transformants, in which the plasmid-borne pykl locus carries a nonsense mutation, appears to implicate the enzyme in the effects on growth. However, the levels of pyk 1 mRNA remained low $(0.6 \%$ of total mRNA). Therefore, these effects appear to be mediated either by high wild-type $P Y K 1$ copy numbers, high $P Y K 1$ mRNA levels, or a combination of both. One possible explanation is that excess $P Y K I$ sequences may inhibit the expression of other essential genes by saturating a factor 
which is required for their expression, but which is present in limiting concentrations. The inhibition of PFK2 mRNA translation by excess PYK1 mRNA (Moore et al., 1990) is consistent with this hypothesis.

Clearly, the PYKI gene is subject to more levels of regulation than most other yeast glycolytic genes. The physiological relevance of this remains an intriguing question, but may relate to the ability of some $p y k l$ alleles to confer cell cycle arrest ( $c d c 19$; Fraenkel, 1982).

We wish to thank many of our colleagues for helpful discussions, and in particular Robert Cafferkey, Andrew Goodey, Teresa McNally, Linda Fothergill-Gilmore, Toby Murcott and Kevin Brindle for sharing their PYKl experiences with us. We are grateful to Jane Mellor for the plasmid pMA91/PYK. Lynn Loughlin deserves recognition for her excellent technical assistance, and Diane Johnstone for her photographic work. A.J.E.B. and P.A.M. were supported by SERC studentships.

\section{References}

Aguilera, A. \& Zimmerman, F. K. (1986). Isolation and molecular analysis of the phosphoglucose isomerase structural gene of Saccharomyces cerevisiae. Molecular and General Genetics 202, 83-89.

ALBER, T. \& KAWASAKI, G. (1982). Nucleotide sequence of the triose phosphate isomerase gene of Saccharomyces cerevisiae. Journal of Molecular and Applied Genetics 1, 419-434.

BEGGS, J. D. (1978). Transformation of yeast by a replicating hybrid plasmid. Nature, London 275, 104-109.

Bennetzen, J. L. \& HALl, B. D. (1982). The primary structure of the Saccharomyces cerevisiae gene for alcohol dehydrogenase I. Journal of Biological Chemistry 257, 3018-3025.

BetTANY, A. J. E. (1988). Messenger RNA translation in Saccharomyces cerevisiae. PhD Thesis, University of Glasgow.

Bettany, A. J. E., Moore, P. A., Cafferkey, R., Bell, L. D., Goodey, A. R., Carter, B. L. A. \& Brown, A. J. P. (1989). 5'secondary structure, in contrast to a short string of non-preferred codons, inhibits the translation of the pyruvate kinase mRNA in yeast. Yeast 5, 187-198.

BURke, R. L., Tekamp-Olson, P. \& Najarian, R. (1983). The isolation, characterization, and sequence of the pyruvate kinase gene of Saccharomyces cerevisiae. Journal of Biological Chemistry 258, 2193-2201.

Chen, C. Y., Oppermann, H. \& Hitzeman, R. A. (1984). Homologous versus heterologous gene expression in the yeast, Saccharomyces cerevisiae. Nucleic Acids Research 12, 8951-8970.

ClifTON, D. \& FraENKEL, D. G. (1981). The gcr (glycolysis regulation) mutation of Saccharomyces cerevisiae. Journal of Biological Chemistry 256, 13074-13078.

Coleman, K., Steensma, H. Y., Kaback, D. B. \& Pringle, J. R. (1986). Molecular cloning of chromosome I DNA from Saccharomyces cerevisiae: isolation and characterization of the CDC24 gene and adjacent regions of the chromosome. Molecular and Cellular Biology 6, 4516-4525.

Feinberg, A. P. \& Vogelstein, B. (1983). A technique for radiolabelling DNA restriction endonuclease fragments to high specific activity. Analytical Biochemistry 132, 6-13.

FrAENKEL, D. G. (1982). Carbohydrate metabolism. In The Molecular Biology of the Yeast Saccharomyces: Metabolism and Gene Expression, pp. 1-37. Edited by J. N. Strathern, E. W. Jones \& J. R. Broach. Cold Spring Harbor, NY: Cold Spring Harbor Laboratory.

FUTCHER, A. B. \& COX, B. S. (1984). Copy number and the stability of 2-micron circle-based artificial plasmids of Saccharomyces cerevisiae. Journal of Bacteriology 157, 283-290.

Gallwitz, D. \& Sures, I. (1980). Structure of a split yeast gene: complete nucleotide sequence of the actin gene in Saccharomyces cerevisiae. Proceedings of the National Academy of Sciences of the United States of America 77, 2546-2550.

Goodey, A. R., Doel, S., Piggott, J. R., Watson, M. E. E. \& CARTER, B. L. A. (1987). Expression and secretion of foreign polypeptides in yeast. In Yeast Biotechnology, pp. 401-429. Edited by D. R. Berry, I. Russell \& G. G. Stewart. London: Allen \& Unwin.

Heinisch, J., Ritzel, R. G., von Borstel, R. C., Aguilera, A., Rodicio, R. \& ZimmermanN, F. K. (1989). The phosphofructokinase genes of yeast evolved from two duplication events. Gene 78 , 309-321.

Hitzeman, R. A., Hagie, F. E., Hayflick, J. S., Chen, C. Y., SEEBURG, P. H. \& DERYNCK, R. (1982). The primary sequence of the Saccharomyces cerevisiae gene for 3-phosphoglycerate kinase. Nucleic Acids Research 10, 7791-7808.

Holland, J. P. \& Holland, M. J. (1979). The primary structure of a glyceraldehyde-3-phosphate dehydrogenase gene from Saccharomyces cerevisiae. Journal of Biological Chemistry 254, 9839-9845.

Holland, M. J., Holland, J. P., Thill, G. P. \& Jackson, K. A. (1981). The primary structures of two yeast enolase genes: homology between the 5 -noncoding flanking regions of yeast enolase and glyceraldehyde-3-phosphate dehydrogenase genes. Journal of Biological Chemistry 256, 1385-1395.

HUNSLEY, J. R. \& SUELTER, C. H. (1969). Yeast pyruvate kinase: II kinetic properties. Journal of Biological Chemistry 244, 4819-4822.

KAWASAKI, G. \& FraENKEL, D. G. (1982). Cloning of yeast glycolytic genes by complementation. Biochemical and Biophysical Research Communications 108, 1107-1112.

Kellermann, E., Seeboth, P. G. \& Hollenberg, C. P. (1986). Analysis of the primary structure and promoter function of a pyruvate decarboxylase gene $(P D C l)$ from Saccharomyces cerevisiae. Nucleic Acids Research 14, 8963-8977.

King, D. J., Walton, E. F. \& Yarranton, G. T. (1989). The production of proteins and peptides from Saccharomyces cerevisiae. In Molecular and Cell Biology of Yeasts, pp. 107-133. Edited by E. F. Walton \& G. T. Yarranton. London: Blackie.

Kingsman, S. M., Kingsman, A. J., Dobson, M. J., Mellor, J. \& ROBERTS, N. A. (1985). Heterologous gene expression in Saccharomyces cerevisiae. Biotechnology and Genetic Engineering Reviews 3, $377-416$.

KopetzKI, E., Entian, K.-D. \& Mecke, D. (1985). Complete nucleotide sequence of the hexokinase PI gene ( $H X K I)$ of Saccharomyces cerevisiae. Gene 39, 95-102.

LeHRaCh, R. H., Diamond, D., WozNey, J. M. \& BoedtKer, H. (1977). RNA molecular weight determinations by gel electrophoresis under denaturing conditions, a critical reexamination. Biochemistry 16, 4743-4751.

LINDQUIST, S. (1981). Regulation of protein synthesis during heat shock. Nature, London 293, 311-314.

MAITRA, P. K. \& LOBO, Z. (1971). A kinetic study of glycolytic enzyme synthesis in yeast. Journal of Biological Chemistry 246, 475-488.

Maniatis, T., JefFrey, A. \& KLEID, D. G. (1975). Nucleotide sequence of the rightward operator of phage lambda. Proceedings of the National Academy of Sciences of the United States of America 72 , 1184-1188.

McNally, T., Purvis, I. J., Fothergill-Gilmore, L. A. \& Brown, A. J. P. (1989). The yeast pyruvate kinase gene does not contain a string of non-preferred codons: revised nucleotide sequence. $F E B S$ Letters 247, 312-316.

Mellor, J., Dobson, M. J., Roberts, N. A., Kingsman, A. J. \& KIngsman, S. M. (1985). Factors affecting heterologous gene expression in Saccharomyces cerevisiae. Gene 33, 215-226.

Moore, P. A., Bettany, A. J. E. \& Brown, A. J. P. (1990). The expression of a yeast glycolytic gene is subject to dosage limitation. Gene 89, 85-92.

Murray, J. A. H., Scarpa, M., Rossi, N. \& Cesarini, G. (1987). Antagonistic controls regulate copy number of the yeast 2-micron plasmid. EMBO Journal 6, 4204-4212.

Parent, S. A., Fenimore, C. M. \& Bostian, K. A. (1985). Vector systems for the expression, analysis and cloning of DNA sequences in Saccharomyces cerevisiae. Yeast 1, 83-138.

Purvis, I. J., Loughlin, L., Bettany, A. J. E. \& Brown, A. J. P. (1987). Translation and stability of an Escherichia coli $\beta$-galactosidase 
mRNA expressed under the control of pyruvate kinase sequences in Saccharomyces cerevisiae. Nucleic Acids Research 15, 7963-7974.

Santiago, T. C., Purvis, I. J., Bettany, A. J. E. \& Brown, A. J. P. (1986). The relationship between mRNA stability and length in Saccharomyces cerevisiae. Nucleic Acids Research 14, 8347-8360.

Santiago, T. C., Bettany, A. J. E., Purvis, I. J. \& Brown, A. J. P. (1987). Messenger RNA stability in Saccharomyces cerevisiae: the influence of translation and poly(A) tail length. Nucleic Acids Research 15, 2417-2429.

SCHAAF, I., Heinisch, J. \& ZimmermanN, F. K. (1989). Overproduction of glycolytic enzymes in yeast. Yeast 5, 285-290.

Schwelberger, H. G., Kohlwein, S. D. \& Paltauf, F. (1989). Molecular cloning, primary structure and disruption of the structural gene of aldolase from Saccharomyces cerevisiae. European Journal of Biochemistry 180, 301-308.

STAChelek, C., Stachelek, J., Swan, J., Botstein, D. \& Konigsberg, W. (1986). Identification, cloning and sequence determination of the genes specifying hexokinase A and B from yeast. Nucleic Acids Research 14, 945-963.
Tekamp-Olson, P., Najarian, R. \& Burke, R. L. (1988). The isolation, characterisation and nucleotide sequence of the phosphoglucoisomerase gene of Saccharomyces cerevisiae. Gene 73, 153-161. ThOMAS, P. S. (1980). Hybridization of denatured RNA and small DNA fragments transferred to nitrocellulose. Proceedings of the National Academy of Sciences of the United States of America 77, 5201-5205.

Watson, H. C., Walker, N. P. C., Shaw, P. J., Bryant, T. N., Wendell, P. L., Fothergill, L. A., Perkins, R. E., Conroy, S. C., Dobson, M. J., Tuite, M. F., Kingsman, A. J. \& Kingsman, S. M. (1982). Sequence and structure of yeast phosphoglycerate kinase. EMBO Journal 1, 1635-1640.

White, M. F. \& Fothergill-Gilmore, L. A. (1988). Sequence of the gene encoding phosphoglycerate mutase from Saccharomyces cerevisiae. FEBS Letters 229, 383-387.

Yoshino, M. \& MuraKami, K. (1982). AMP deaminase reaction as a control system of glycolysis in yeast: activation of phosphof ructokinase and pyruvate kinase by the AMP deaminase-ammonia system. Journal of Biological Chemistry 257, 2822-2828. 